\title{
Medical Abortion Versus Manual Vacuum Aspiration in a Hilly District Hospital of Eastern Nepal: A Comparative Study
} Panta OB, Bhattarai D, Parajuli N

\author{
Department of Radiology and Imaging \\ District Hospital Khotang \\ Khotang, Nepal \\ Corresponding Author \\ Om Biju Panta \\ Department of Radiology and Imaging \\ District Hospital Khotang \\ Khotang, Nepal \\ Email: bijupanta@yahoo.com
}

\section{Citation}

Panta OB, Bhattarai D, Parajuli N. Medical Abortion Versus Manual Vacuum Aspiration in a Hilly District Hospital of Eastern Nepal: A Comparative study. Kathmandu Univ Med J 2013;43(3):206-209.

\section{ABSTRACT}

\section{Backgroud}

Nepal government has approved medical abortion and manual vacuum aspiration for early first trimester pregnancy. Both the procedures have been approved by World Health Organization for use in early first trimester.

\section{Objectives}

The study aims to compare efficacy and safety of medical abortion with surgical abortion in a district hospital of rural eastern Nepal.

\section{Method}

An observational study conducted in district hospital, dhankuta from July 2010 to January 2011. Clients for abortion services were counseled about methods of abortion and were allowed to make decision on their own and classified as medical abortion group ( $\mathrm{N}=48$ ) (receiving 200milligram Mifepristone followed by 800 microgram misoprostol sublingually or vaginally on day two)and manual vacuum aspiration group ( $\mathrm{N}=36)$. The two groups were compared for rate of complete abortion and other complications and contraception use after procedure.

\section{Results}

Rate of complete abortion was similar in both groups, $95.8 \%$ among medical abortion and $97.2 \%$ in manual vacuum aspiration. Moderate to severe expulsion bleeding was reported in $91.6 \%$ of cases after Medical Abortion but none required medical attention for hemorrhage. Condom was the most preferred contraceptive in medical abortion group and depo provera in manual vacuum aspiration group.

\section{Conclusion}

Medical method of abortion using mifepristone and misoprostol is equally safe and effective as manual vacuum aspiration in rural setting district hospitals of Nepal.

\section{KEY WORD}

Contraception, manual vacuum aspiration, medical abortion

\section{INTRODUCTION}

Nepal government developed national strategy on use of medical abortion and launched pilot study on medical abortion in 2008 in six districts of the country. ${ }^{1}$ Medical abortion has been reported to have a slightly lower failure rate compared to surgical abortion for early first trimester abortion (within seven weeks). ${ }^{2}$ However, studies show both method to be equally well acceptable provided client are allowed to make decision. ${ }^{3}$ WHO has declared medical methods of abortion to be safe and effective and has listed mifepristone and misoprostol in its model list of essential medicines. ${ }^{4,5}$ This study aims to compare the safety of medical abortion with previously established manual vacuum aspiration.

\section{METHODS}

The study was a prospective non interventional observational study conducted in a hilly district hospital at Dhankuta over a period of six months from July 2010 
to January 2011. All clients with pregnancy of up to 63 days from last menstrual period who came for termination of pregnancy were included in the study. The period of gestation of clients were confirmed by per vaginal examination and ultrasound. Clients wanting termination of pregnancy were counseled about medical method (using mifepristone and misoprostol) and manual vacuum aspiration. They were allowed to make their decision on their own and classified in two groups Medical Abortion (MA) ( $N=48)$ and Manual Vacuum Aspiration (MVA) $(\mathrm{N}=36)$. Clients were informed about their inclusion in the study and written consent was taken.

Comprehensive abortion care service was given by trained medical practitioner. Clients in MA group were given Nepal government approved regime (i.e. Mifepristone $200 \mathrm{mg}$ orally followed by Domiciliary Misoprostol $800 \mathrm{mcg}$ sublingually or Vaginally whichever is comfortable to the patient after $24 \mathrm{hrs}$ of Mifepristone) and those in the MVA group were pre-medicated with ibuprofen and Diazepam; and paracervical block was used for anesthesia. Manual vacuum aspiration was performed with IPAS double valve syringe and no 5 to 8 plastic canula as required. Patients were called on $15^{\text {th }}$ day of procedure for follow up and accessed for outcome and complications. A check ultrasound was done to assess completion of procedure.

Data was collected in a pre designed performa. Rate of complete abortion was noted in both groups. Other outcomes noted were post procedure bleeding and complications requiring referral. Contraceptives were offered to both groups and the usage was compared. Age, parity, education was compared in two groups. Clients were considered illiterate if they were not able to write or sign their name. Amount of hemorrhage was recorded as reported by clients. Changing of completely soaked pads up to three times per day was considered minimal hemorrhage, 4-6 times was considered moderate hemorrhage and more than six times was considered severe hemorrhage. Data were analyzed using SPSS version 16.0. Rate of completion and complications were compared using Chi square test. A $p$-value of less than 0.05 was considered to be statistically significant.

\section{RESULTS}

Both groups were very similar with regards to age, parity, literacy, marital status. Most belonged to the ethnic code 2 (Mongolian) in both groups (Table-1). However, clients with education above high school were higher in MA group [28/48(58.4\%)] as compared to MVA group [14/36(38.9\%)] but did not reach level of statistical significance $(p=0.12)$.

The primary outcome i.e. complete expulsion of product of conception was higher in MVA group [35/36(97.2\%)] as compared to MA group [46/48(95.8\%)] but the difference is not significant statistically $(p=0.64)$. One incomplete abortion seen in MVA group occurred in a 30 years G4P2
Table 1. Characteristics of the client.

\begin{tabular}{|c|c|c|c|c|}
\hline & \multicolumn{2}{|l|}{$M A(N=48)$} & \multicolumn{2}{|l|}{ MVA (N=36) } \\
\hline & $\begin{array}{l}\text { Mean } \pm S D \\
\text { (Range) }\end{array}$ & Number & $\begin{array}{l}\text { Mean } \pm S D \\
\text { (Range) }\end{array}$ & Number \\
\hline Age Mean & $\begin{array}{l}27.06 \pm 6.29 \\
(17-42)\end{array}$ & & $\begin{array}{l}27.53 \pm 7.36 \\
(17-44)\end{array}$ & \\
\hline $\begin{array}{l}\text { POG } \\
\text { (weeks) }\end{array}$ & $6.71 \pm 1.1(4-9)$ & & $\begin{array}{l}7.06 \pm 1.05 \\
(5-9)\end{array}$ & \\
\hline POG (days) & $\begin{array}{l}45.1 \pm 6.8 \\
(30-63)\end{array}$ & & $\begin{array}{l}50.02 \\
\pm 7.2(37-63)\end{array}$ & \\
\hline $\begin{array}{l}\text { Parity : } \\
\text { Primi }\end{array}$ & & $11(22.9 \%)$ & & $8(22.2 \%)$ \\
\hline Multi & & 37 (77.1\%) & & $28(77.8 \%)$ \\
\hline \multicolumn{5}{|c|}{ Marital status: } \\
\hline Married & & $46(95.8 \%)$ & & $35(97.2 \%)$ \\
\hline Unmarried & & $2(4.2 \%)$ & & $1(2.8 \%)$ \\
\hline \multicolumn{5}{|c|}{ Ethnic Code* } \\
\hline 1( Dalits) & & $2(4.2 \%)$ & & $2(5.6 \%)$ \\
\hline $\begin{array}{l}\text { 2(Rai, } \\
\text { Magar, } \\
\text { tamang, } \\
\text { limbu) }\end{array}$ & & $22(45.8 \%)$ & & $22(61.1 \%)$ \\
\hline $\begin{array}{l}\text { 5(Newar, } \\
\text { gurung, } \\
\text { thakali) }\end{array}$ & & $6(12.5 \%)$ & & $4(11.1 \%)$ \\
\hline $\begin{array}{l}\text { 6(Bramhin, } \\
\text { chettri, } \\
\text { thakuri, } \\
\text { sanyasi) }\end{array}$ & & $18(37.5 \%)$ & & $8(22.2 \%)$ \\
\hline \multicolumn{5}{|l|}{ Literacy } \\
\hline Literate & & $37(77.1 \%)$ & & $24(66.7 \%)$ \\
\hline Illiterate & & $11(22.9 \%)$ & & $12(33.3 \%)$ \\
\hline
\end{tabular}

*1- Damai, Kami, Sarki, Gayine; 2- Rai, Magar, Tamang, Limbu, 5- Newar, Gurung, Thakali, 6- Bramhin, Chettri, Thakuri, Sanyasi; 3 and 4 are predominantly residents of Terai region.

Table 2. Complications in relation to period of gestation.

\begin{tabular}{|lll|}
\hline $\begin{array}{c}\text { Complication } \\
\text { POG(wks) }\end{array}$ & \multicolumn{1}{c|}{ Medical Abortion } & \multicolumn{1}{c|}{ Manual Aspiration } \\
\hline$<6$ weeks & Pain & Pain \\
& Expulsion Bleeding & \\
& Nausea and vomiting & \\
\hline 7-9 weeks & Incomplete (1) & Incomplete (1) \\
\hline & Failure (1) & Pain \\
\hline 10-12 weeks & Pain & \\
& Only Clients with POG up to 9wks (63 days) included \\
\hline
\end{tabular}

at eight weeks gestation with one previous abortion. The client was managed with MVA. In MA group, total of two patients faced complications. First one incomplete abortion occurred in a 25 years G3P2 lady at eight weeks gestation ( 55 days), and one failure occurred in a 37 years G5P4 lady at eight weeks gestation (56 days), both of them were managed with MVA. (Table-3) 
Pain during the procedure was the main complain in the MVA group [28(77.7\%)] (Table-3). Expulsion hemorrhage was the main complain with moderate to severe bleeding in 44 (91.6\%)followed by pain abdomen and nausea and vomiting in the MA group. No complication required referral to a higher center arouse during the study period.

Table 3. Outcome.

\begin{tabular}{|c|c|c|c|}
\hline & $M A(N=48)$ & MVA (N=36 & P-Value \\
\hline \multicolumn{4}{|l|}{ Primary Outcome } \\
\hline Complete & $46(95.8 \%)$ & $35(97.2 \%)$ & \multirow{3}{*}{0.64} \\
\hline Failure & $1(2.1 \%)$ & --- & \\
\hline Incomplete & $1(2.1 \%)$ & $1(2.8 \%)$ & \\
\hline \multicolumn{4}{|l|}{ Other outcomes } \\
\hline Expulsion Hemorrhage: & $44(91.6 \%)$ & --- & \\
\hline Pain: & $36(75.0 \%)$ & $28(77.7 \%)$ & \\
\hline Nausea/Vomiting: & $33(68.7 \%)$ & --- & \\
\hline
\end{tabular}

In MVA group, Depo provera [21(58.3\%)] was the most popular contraceptive followed by condom, and oral contraceptive pills (Table-4). Condom [38(79.2\%)] was the most popular contraceptive in the MA group, followed by oral contraceptive pills and Depo provera (Table-4).

Table 4. Contraceptive acceptance after MA and MVA.

\begin{tabular}{lll} 
Contraception & MA (N=48) & MVA (N=36) \\
\hline Depo Provera & $5(10.4 \%)$ & $21(58.3 \%)$ \\
$\begin{array}{l}\text { Oral Contraceptive } \\
\text { Pills }\end{array}$ & $5(10.4 \%)$ & $6(16.7 \%)$ \\
Condoms & $38(79.2 \%)$ & $9(25 \%)$
\end{tabular}

\section{DISCUSSION}

During our study period medical abortion [48(57.1\%)] was preferred by more women than manual vacuum aspiration [36(42.8\%)], the finding is in concordance with other studies comparing MVA and MA. ${ }^{6,7}$ The reason for preference to medical abortion may be because of its non invasive nature and also hesitancy seen in women for internal examination especially in our context. The client's age, sex and parity in both group are comparable, this has helped to reduce confounding factors and bias in the research even without randomization. Clients with education above high school were found to choose medical abortion more frequently, which is similar to finding of Das et. al. done in India. The study showed medical abortion was preferred by urban, educated population in upper socio-economic strata. The reason for this may be better awareness and confidence of using misoprostol among the educated population. Intervention in form of health education and awareness promotion about medical methods of abortion targeting rural population, belonging to low socioeconomic strata and uneducated group may help improve awareness among these people.

The outcome of treatment i.e. rate of complete abortion was comparable in both groups, a finding similar to previously established findings. ${ }^{3,7}$ The rate of complete abortion with MA was $95 \%$ which is comparable with previous results from studies in Nepal and other countries. ${ }^{1,2,4,7,8}$ Similarly rate of complete abortion with MVA was $97.2 \%$, a result similar to previous studies and reviews. ${ }^{3,4,9}$

In the MA group, moderate to severe expulsion hemorrhage was noted by $91 \%$ of patient; however there were no emergency visit to hospital for excessive bleeding and no patient reported having symptoms suggestive of hypovolemic shock. Expulsion pain was reported by $75 \%$; nausea and vomiting was reported by $68 \%$. There were no cases requesting conversion to surgical abortion or requiring conversion to surgical abortion for pain or hemorrhage before follow up time. The findings are similar to findings of previous studies that the frequency of severe hemorrhage requiring haemostatic curettage is low. ${ }^{3}$ However, the reported rate of complications that is bleeding and pain was higher in this study as compared other studies, this variation might be a result of subjective variation and exaggeration by patient. ${ }^{3,10}$

Contraception was offered to all clients following the procedure and every client accepted at least one modern method of contraception. Condom was the most popular method in MA group, it was also seen that condom use was predominantly in younger age group, a finding similar to a study conducted by Karki et. al. ${ }^{11}$ In MVA group the finding was reverse with Depo Provera being the most popular method of use. The pattern of acceptance of contraception needs further study.

\section{CONCLUSION}

Medical abortion regime is safe to be used as an alternative to manual vacuum aspiration in rural setup district hospitals. Targeted health education package for illiterate people, with low socioeconomic background and with low level education regarding medical abortion is required.

There were few limitations to this study. The number of clients involved in the study was less. The two study group was not matched for confounding variables. Assigning of clients to either group was not randomized or blinded, thus leaving a possibility of bias during client counseling. The complications were reported as perceived by clients and were susceptible to subjective variation. The duration of bleeding and time of expulsion of Product of Conception (POC) from medication was not analyzed in the study.

\section{ACKNOWLEDGEMENT}

We gratefully acknowledge the support and cooperation of the district health office of Dhankuta and all staffs of Dhankuta hospital directly or indirectly involved in Clients' management. 


\section{REFERENCES}

1. Karki C, Pokharel H, Kushwaha A, Manandhar D, Bracken H, Winikoff B. Acceptability and feasibility of medical abortion in Nepal. Int J Gynaecol Obstet. 2009; 106(1):39-42.

2. Royal College of Obstetricians and Gynaecologists (RCOG). The care of women requesting induced abortion: Evidence-based clinical guideline number 7. London: RCOG, 2004.

3. Bygdeman M, Danielsson KG. Options for early therapeutic abortion. A comparative review. Drugs. 2002;62:2459-70.

4. World Health Organization (WHO). Safe abortion: Technical and policy guidance for health systems. Geneva: WHO, 2003.

5. World Health Organization (WHO). WHO model list of essential medicines. 15th ed. Geneva: WHO;2007.

6. Ashok PW, Kidd A, Flett GM, Fitzmaurice A, Graham W, Templeton A. A randomized comparison of medical abortion and surgical vacuum aspiration at 10-13 weeks gestation. Hum. Reprod. 2002;17(1): 92-8.

7. Das V, Jain S, Gupta HP, Agarwal A, Agarwal S, Pandey A. Evaluation of newer methods of early pregnancy termination. J Obstet Gynaecol India. 2005; 55(5):454-6.
8. Faúndes A, Fiala C, Tang OS, Velasco A. Misoprostol for the termination of pregnancy up to 12 completed weeks of pregnancy. Int J Gynaecol Obstet.2007; 9: S172-7.

9. Maclsaac L, Darney P. Early surgical abortion: An alternative to and backup for medical abortion. Am J Obstet Gynecol. 2000; 183(2):7683.

10. Chawdhary R, Rana A, Pradhan N. Mifepristone plus vaginal misoprostol vs vaginal misoprostol alone for medical abortion in gestation 63 days or less in Nepalese women: A quasi-randomized controlled trial. J Obstet Gynaecol Res. 2009;35(1):78-85.

11. Karki YB, Basnett I, Clark KA, Ganatra B, Stucke S. An Exploratory Study of Complications from CAC: Improvement of the Quality of Comprehensive Abortion Care (CAC) Services in Nepal [Internet]. Kathmandu: IPAS-Nepal; 2009[cited 2011 January 12] Report No : CACNEP-E09Available. From: http://www.ipas.org/Publications/ asset_upload_file704_4397.pdf. 